Individual Differences in the Pursuit of Self-uniqueness Through Consumption

\author{
Michael Lynn, Cornell University \\ Judy Harris, Florida International University
}

In this paper, we report an original study of the relationships between selfattributed need for uniqueness and several consumer dispositions. The results indicate that the self-attributed need for uniqueness is related to consumers' desires for scarce, innovative, and customized products and to consumers' preferences for unusual shopping venues, but not to consumers' susceptibilities to normative influence. Moreover, we find that these relationships are mediated by a latent variable reflecting individual differences in the tendency to pursue uniqueness through consumption. The theoretical and practical implications of these results are discussed along with directions for future research.

Many consumers feel a need to be special and unique, so they seek goods, services, and experiences that will distinguish them from the multitude of other consumers. Marketers frequently appeal to this consumer need for uniqueness through advertising messages like the following:

Although the McCooey brothers and their sister have always been reminded of their striking similarities, it is their differences they have always insisted on. It's no wonder then that each owns a different Waterman pen.

- Advertisement in Newsweek

At 650 dollars a bottle, not many people have the opportunity to experience the exceedingly rare The Glenlivet's 21 -year-old single malt Scotch.

- Advertisement in Fortune

This beautiful Baccarat crystal designed and created exclusively for Garrard, the Crown Jewellers of England... So, what could come only from us really could belong only to you.

- Advertisement in Connoisseur

Although the theme of these ads is uniqueness, the use of that theme is not unique to these examples. One study of 2,000 ads randomly sampled from bestselling magazines in each decade from 1900 to 1980 found that uniqueness appeals were used as a central theme in $10 \%$ of the ads and were used as a subordinate theme in $23 \%$ of the ads (Pollay, 1984). Of course, advertising is not the only means that marketers use to appeal to uniqueness motives. As illustrated in the advertising messages above, product differentiation, prestige pricing, and exclusive distribution are also components of 
marketers' appeals to consumers' needs for uniqueness.

Despite the frequency with which marketing practitioners appeal to consumers' needs for uniqueness, academic researchers have rarely studied this motive and its impact on consumer behavior. In this paper, we address this deficiency in the literature. First, we introduce social psychological theory on the need for uniqueness, discuss its relevance to consumer behavior, and critically review existing consumer research on this topic. Then, we present an original study that tests hypothesized relationships between individual differences in the need for uniqueness and various consumer dispositions. Finally, we discuss the theoretical and practical implications of this study's results along with directions for future research.

\section{Uniqueness Theory}

Uniqueness theory (Snyder \& Fromkin, 1980) deals with people's emotional and behavioral reactions to information about their similarity to others. ${ }^{1}$ According to the theory, people find high levels of similarity and dissimilarity unpleasant, and therefore seek to be moderately distinct from others. In a test of this hypothesis, Fromkin (1972) gave students false feedback about how similar their responses on a lifestyle survey were to those of other respondents, and then asked the students to rate their own moods. Consistent with the prediction of uniqueness theory, he found that the students who were told that they were moderately similar to other respondents reported more positive moods than did students who were told that they were either highly similar or highly dissimilar to other respondents.

According to uniqueness theory, people seek to avoid the unpleasant affect associated with extreme similarity and dissimilarity by striving to maintain moderate levels of self-distinctiveness. This means that as people perceive more similarity between themselves and others, they become motivated to establish their dissimilarity or uniqueness. In several tests of this hypothesis, people who were led to believe that they were highly similar to many others conformed less in a judgment task (Duval, 1972), generated more unusual uses for an object (Fromkin, 1968), and placed more value on scarce experiences (Fromkin, 1970) than did others. Thus, people do appear to seek uniqueness. However, this uniqueness striving is constrained by the need for social affiliation and social approval, so people strive to be unique in ways that do not result in social isolation or disapproval (Snyder \& Fromkin, 1980).

The central tenet of uniqueness theory is that everyone has a need to be moderately

\footnotetext{
${ }^{1}$ Also relevant to this topic is work on individuation (Maslach, Stapp, \& Santee, 1985; Ziller, 1964), optimal distinctiveness (Brewer, 1991), and social differentiation (Codol, 1984; Lemaine, 1974)
} 
dissimilar to others. However, Snyder and Fromkin $(1977,1980)$ also argue that there are individual differences in the strength of this need. The stronger an individual's need for uniqueness, the more dissimilar to others he or she wants to be, and the more sensitive he or she is to similarity information (Snyder, 1992). To test these predictions, Snyder and Fromkin (1977) developed a scale measuring individual differences in the need for uniqueness. They found that people who scored high on the scale were more likely than people who scored low to join unique groups, such as a women's liberation group and a gay rights group. Additionally, scores on the scale were positively related to the size of subjects' signatures and to how dissimilar they rated themselves in comparison to another person (Snyder \& Fromkin, 1977).

\section{Products as Sources of Uniqueness}

Possessions are often extensions of the self (Belk, 1989; James, 1890 ), so one way to differentiate the self from others is by possessing unique consumer products (Fromkin, 1971 ; Snyder, 1992). Consumers may enhance or express feelings of self-uniqueness by acquiring products whose scarcity, newness, or relative unpopularity means that few others will possess them. They may also pursue self-uniqueness by shopping at small, less frequented stores or by customizing commonlyowned products. In the paragraphs that follow, we further discuss these consumer behaviors and develop hypotheses about their relationships with individual differences in the need for uniqueness.

Desire for Scarce Products

Over 200 years ago, Adam Smith (1776/1937) noted that ". . the merit of an object that is to any degree either useful or beautiful, is greatly enhanced by its scarcity" (p. 172). Modern consumer research has supported Smith's claim (see Lynn, 199 1, for a review). Scarcity has been found to enhance the attractiveness of records and clothing (Brehm, Stires, Sensenig, \& Shaban, 1966; Szybillo, 1973, 1975); the desirability of leather boots and wine (Fromkin, Williams, \& Dipboye, 1973; Lynn,1989); the perceived quality of chairs and art prints (Atlas \& Snyder, 1978); and the tastes of cookies, dormitory food, and soft drinks (Ringold, 1988; West, 1975; Worchel, Lee, \& Adewole, 1975).

The need for uniqueness provides one explanation for scarcity's enhancement of product desirability (see Lynn, 1992, for a list of other explanations). Since fewer people can possess scarce products than can possess nonscarce ones, consumers may desire scarce products as a way to differentiate themselves from others (Brock, 1968; Snyder \& Fromkin, 1980). Consistent with this explanation, researchers have found that scarcity's enhancement of desirability is greater for subjects 
whose need for uniqueness is strengthened by information that they are highly similar to many others (Fromkin, 1970; Powell, 1974; however, see Okamoto, 1983). To the extent that some consumers have stronger dispositional needs for uniqueness than do others, there should be corresponding individual differences in the desire for scarce products.

Hypothesis 1. Individual differences in the need for uniqueness will be positively related to the desire for scarce products.

\section{Consumer Innovativeness}

New products rarely gain immediate and widespread acceptance. Typically, new products are first adopted by a relatively small group of consumer innovators who then influence later adopters (Robertson, 1971; Rogers, 1983). Adopting new products before others do is one way of being different. Thus, consumers' innovativeness may be motivated, in part, by a desire to be unique (Burns \& Krampf, 1992; Fromkin, 1971).

Some support for this expectation is provided by Szybillo's (1975) finding that fashion opinion leaders displayed a stronger preference for scarce fashions than did nonopinion leaders. Although innovativeness and opinion leadership are not identical, opinion leaders do need to be relatively early adopters of new products in order to be in a position to influence the purchase decisions of others. Moreover, empirical research has found that opinion leaders are more innovative than are nonopinion leaders (Myers \& Robertson, 1972). Thus, Szybillo's results are consistent with a relationship between consumer innovativeness and the need for uniqueness. These conceptual and empirical considerations suggest that consumers will be more innovative the greater their dispositional needs for uniqueness.

Hypothesis 2: Individual differences in the need for uniqueness will be positively related to consumer innovativeness.

\section{Consumer Conformity}

Consumers' brand preferences and choices often conform to those of relevant others (Reingen, Foster, Brown, \& Seidman, 1984; Venkatesan, 1966; Witt \& Bruce, 1972). This conformity can be attributed to two types of social influence-informational and normative (Bearden, Netemeyer, \& Teel, 1989). Informational influence is reflected by a person's tendency to use other people's behavior as a source of information about the objectively best course of action. Normative influence is reflected by the use of conformity to gain rewards and avoid punishments, as well as by the desire to be associated with and similar to other people. Since conformity enhances the similarity between people, the need for uniqueness may inhibit conformity-especially conformity resulting from 
normative influence. Consistent with this explanation, Duval (1972) found that people conformed less on a judgment task when their need for uniqueness was enhanced by false information that they were very similar to many others. This finding suggests that consumers with a strong dispositional desire to be unique may resist social influence in order to select less popular brands that convey more distinctiveness.

Hypothesis 3: Individual differences in the need for uniqueness will be negatively related to consumer susceptibility to social influence.

\section{Choice of Shopping Venue}

Consumers face numerous alternatives when deciding where to shop. Department stores, discount outlets, specialty shops, flea markets, thrift shops, garage sales, catalogues, and television shopping networks are but a few of the outlets available to shoppers. One motive likely to underlie consumers' decisions about where to shop is the need for uniqueness. Consumers with strong desires to be unique may prefer to shop at smaller, less popular retail outlets that carry unique merchandise, rather than at larger and more popular retail outlets that carry standard or common merchandise.

Ethnographic research on alternative marketing systems provides support for this contention.

Belk, Sherry, and Wallendorf (1988) characterize the Red Mesa Swap Meet as "extoll[ing] rugged individualism...in word, deed and in product offerings" (p. 464). They also describe many of the customers as "shopping to find something unexpected," (p. 460) and characterize swap meets in general as "treasure hunts" (p. 458). Similar themes are apparent in Sherry's (1990) analysis of the Dalton Valley flea market. Many of the consumers he quotes characterize the flea market as more personal than a mall. The goods are described as "unique, not mass produced," and as having personal stories. Moreover, shopping at the flea market seems to be a scarce commodity. As one informant points out, "you can go [to a mall] any time you want," but the market is open only on Sundays.

Quantitative research also suggests that uniqueness motives impact store choice. Gutman and Mills (1 982) found that "fashion leaders" and "fashion independents," who tended to describe themselves as "different" and "standing out in a crowd," shopped at department and specialty stores (such as Bullock's and Neiman-Marcus) more and shopped at mass merchandisers (such as Sears and KMart) less than did other consumer segments. More recently, Darley and Lim (1 993) found that the frequency with which consumers patronize a thrift store was predicted in part by the strength of their agreement with the statement that thrift stores "offer the best selection of unique merchandise." Thus, consumers with a strong dispositional need for uniqueness should frequent smaller, less popular retail outlets more than do consumers with a weaker need for uniqueness. 
Hypothesis 4: Individual differences in the need for uniqueness will be positively related to the preference for unique shopping venues.

\section{Customization of Products}

Increasingly, marketers are offering the opportunity to customize otherwise common products. For example, Hallmark recently introduced "Personalize It!" machines, which allow customers to print their own messages on greeting cards. Among the other products that marketers are beginning to customize are term insurance policies, magazines, and perfumes. Despite the increasing popularity of customization, we could find no research on consumers' reactions to customization opportunities. The desire to be unique is one factor that is likely to influence consumers' responses to such opportunities because customization makes the product that a consumer receives different from that received by others. Thus, customization provides a means of enhancing or expressing feelings of uniqueness, and consumers with a strong dispositional need for uniqueness should respond more favorably to customized products and services than do consumers with a weaker need for uniqueness.

Hypothesis 5: Individual differences in the need for uniqueness will be positively related to the desire to customize products.

The Pursuit of Uniqueness through Consumption

One issue that has not been addressed in the existing literature is whether or not people have characteristic, preferred ways of differentiating themselves from others. It seems likely that people do pursue self-uniqueness in characteristic ways and that some people seek uniqueness through consumption, while others seek uniqueness in other ways. If so, then the relationships that exist between individual differences in the need for uniqueness and various consumer behaviors and dispositions should be mediated by a latent variable that reflects individual differences in the tendency to pursue uniqueness through consumption.

Hypothesis 6: Relationships between individual differences in the need for uniqueness and consumer dispositions should be mediated by a latent variable reflecting individual differences in the tendency to pursue uniqueness through consumption.

\section{Previous Research}

A few researchers have already examined the effects of individual differences in the need for uniqueness on consumer preference for scarce products, consumer innovativeness, consumer conformity, and consumer choice of shopping venue. Unfortunately, this research has produced weak and inconsistent results. For example, Fromkin et al. (1973) and Lynn (1987) found that people with a 
high dispositional need for uniqueness valued scarce things more than did people with a low dispositional need for uniqueness. However, Atlas and Snyder (1978), Dutcher (1975), Hudson (1979), and Lynn $(1987,1989)$ have all failed to replicate this effect.

In addition, Burns (1987, 1989, 1990; Burns \& Rayman, 1991) has also been relatively unsuccessful in his attempts to find reliable differences in the innovativeness of high and low need-foruniqueness consumers. He has found some relationships between the need for uniqueness and passage through different stages in the adoption of innovations, but the stages that were related to uniqueness motivation were few in number and differed across studies and samples. Moreover, some of the significant relationships were in a direction opposite the one predicted.

Furthermore, Schroeder (1990) and Tepper (1 994) have found inconsistent relationships between individual differences in the need for uniqueness and consumer conformity. Schroeder found that scores on Snyder and Fromkin's (1977) Need for Uniqueness Scale were negatively related to several different measures of consumer conformity, but were unrelated to numerous other measures of the construct. Tepper found that high need-for-uniqueness men were more likely than low need-foruniqueness men to give "nontraditional" Valentine's Day gifts, but not to give "unique" gifts. Moreover, the need for uniqueness was unrelated to the types of gifts that women gave.

Finally, Burns (1994) has found weak and inconsistent relationships between the need for uniqueness and out shopping. He found a correlation of .12 between consumers' needs for uniqueness and their tendencies to shop at regional shopping malls other than the ones closest to their residences. However, the need for uniqueness was not related to whether or not consumers rated the shopping malls closest to their homes as their favorite malls.

The weak and inconsistent research results described above may be due to the measures of the predicted and predictor variables that were used. Much of the existing need for uniqueness research has tried to predict fairly specific consumer behaviors or attitude. ${ }^{2}$ For example, research on consumers' response to product scarcity has generally involved only one or two products (Atlas \& Snyder, 1978; Hudson, 1979; Lynn, 1987). Schroeder's (1990) research on consumer conformity used

\footnotetext{
${ }^{2}$ Burns' research $(1987,1989,1990)$ is an exception. He developed a list of 20 new consumer products from several product categories and measured the number of these new products that subjects were aware of; the percentages of the products that subjects were aware of that they were also interested in and had considered adopting; and the percentages of the products under consideration that the subjects tried, rejected (with and without trial), and adopted. However, the reduction in the base number of products in the later adoption stages (only those products in awareness and under consideration were used) may have contributed to the insignificant results involving those stages
} 
multiple stimuli, but focused on separate reactions to each stimulus rather than on indexes that averaged responses across stimuli. In addition, Tepper's (1994) research on conformity to gift-giving norms examined only one gift-giving occasion. In general, personality traits are more predictive of behaviors over multiple events than they are of single behaviors (Epstein, 1979), so the failure to find consistent and strong consumer behavior correlates of the need for uniqueness may be due (in part) to the narrow sample of behaviors that were measured and analyzed.

The measure of individual differences in the need for uniqueness that has typically been used in past research may also help to account for the failure to find robust correlations with consumer behaviors. All of this research (with the exceptions of Dutcher, 1975, and Fromkin et al., 1973) employed Snyder and Fromkin's (1977) Need for Uniqueness Scale. This personality scale has three underlying factors, which Snyder and Fromkin (1977) label (a) a lack of concern for the reactions of others, (b) a desire to not always follow rules, and (c) a willingness to publicly defend one's beliefs (see Table 1 for a sample of items loading on each factor). One problem with this scale is that it places too heavy an emphasis on public and socially risky displays of uniqueness. Disregarding others' reactions, breaking rules, and publicly disagreeing with others are ways of being unique, but they risk angering and alienating others. People can also pursue uniqueness through more private or socially acceptable behaviors. Indeed, Snyder and Fromkin (1980) argue that people prefer socially acceptable ways of being unique. Thus, their scale is biased in that it does not measure the most important manifestations of uniqueness motives. This may help to explain why it has proven to be a poor predictor of some consumer behaviors.

Table 1

Sample Items Loading on Snyder and Fromkin's (1977) Three-Factor Need for Uniqueness Scale

Factor 1: Lack of concern regarding the reactions of others

I am unable to express my feelings if they result in undesirable consequences. ( $\mathrm{R}$ )

It bothers me if people think I am being too unconventional. (R)

I would rather be just like everyone else than be called a freak. (R)

Factor 2: Desire to not always follow rules

I always try to follow rules. (R)

I must admit I find it hard to work under strict rules and regulations.

I find it sometimes amusing to upset the dignity of teachers, judges, and "cultured" people.

Factor 3: Willingness to publicly defend beliefs

I speak up in meetings in order to oppose those who I feel are wrong.

As a rule, I strongly defend my own opinions.

When I am in a group of strangers, I am not reluctant to express my opinion publicly.

Note. Items reversed for scoring are followed by (R). 


\section{The Present Study}

In the present study, we examine the impact of individual differences in the need for uniqueness on consumer dispositions. Specifically, we test Hypotheses 1 through 6 by assessing the relationships between self-reports of the need for uniqueness and self-reports of the desire for scarce products, consumer innovativeness, susceptibility to normative influence, the preference for unique shopping venues, and the desire to customize products. The study addresses the measurement problems in the existing literature by measuring consumer dispositions rather than specific consumer behaviors, and by developing and using a new measure of self-attributed need for uniqueness (SANU) as well as Snyder and Fromkin's (1977) measure of the need for uniqueness (NU).

\section{Method}

Subjects. The subjects in this study were 142 MBA students from a large urban university in the southwestern United States. Although not representative of the population at large, these subjects were generally older people with more work and consumer experience than the typical student sample. This convenience sample was judged to be appropriate because the purpose of the research was to test relationships between variables rather than to generalize subjects' responses to a particular population.

Procedure and scales. The subjects were given a booklet to take home, complete, and return in exchange for extra class credit. This booklet contained (in the following order) self-report measures of(a) the self-attributed need for uniqueness, (b) the need for uniqueness (Snyder \& Fromkin, 1977), (c) the desire for scarce products, (d) the desire for customized products, (e) the preference for unique shopping venues, (f) consumer innovativeness (Goldsmith \& Hofacker, 1991), and (g) consumer susceptibility to normative influence (Bearden et al., 1989). Three of the scales- that is, Snyder and Fromkin's (1977) Need for Uniqueness Scale, Goldsmith and Hofacker's ( 1991 Innovativeness Scale ${ }^{3}$, and Bearden et al.'s (1989) Consumer Susceptibility to Normative Influence subscale-were borrowed from the existing literature. The remaining scales were developed by the authors after a review of the consumer personality literature failed to turn up acceptable existing measures of the constructs. These study-specific scales are presented in the Appendix. Evidence for the reliability of these scales is

\footnotetext{
${ }^{3}$ Goldsmith and Hofacker's (1991) scale was constructed as a measure of product-specific innovativeness and its items contain blank spaces to be filled in with the name of the particular product being studied. Rather than using a particular product name, we completed the scale items with the generic terms "product," "products," or (for Item 3) "innovative/new products." These generic terms allowed respondents to think about any relevant product category or categories when completing the scale.
} 
provided in the following section of this paper, and evidence of their nomological validity is provided in the tests of our hypotheses.

Table 2

Values of Cronbach's Coefficient Alpha for the Scales in This Study

\begin{tabular}{lc}
\multicolumn{1}{c}{$\begin{array}{c}\text { Scales } \\
\text { (in booklet order) }\end{array}$} & $\begin{array}{c}\text { Values of Cronbach's } \\
\text { coefficient alpha }\end{array}$ \\
Self-attributed need for uniqueness & .80 \\
Need for uniqueness (Snyder \& Fromkin, 1977) & .80 \\
Desire for scarce products & .93 \\
Desire for customized products & .63 \\
Preference for unique shopping venues & .78 \\
Consumer innovativeness (Goldsmith \& & .74 \\
$\quad$ Hofacker, 1991) & .92 \\
Consumer susceptibility to normative influence &
\end{tabular}

Results

Reliability of measures. The internal reliabilities of the scales in this study were assessed using Cronbach's coefficient alpha. The alpha values for the scales, which ranged from .63 to .93, suggest that all of the scales are reasonably reliable. However, the analysis indicated that the internal reliabilities of both the consumer innovativeness scale $(a=.68)$ and the preference for unique shopping venues scale $(a$ $=.72$ ) could be substantially improved by dropping one item from each scale (Item 5 in both cases). Dropping these items resulted in new coefficient alphas of .74 for the innovativeness scale and .78 for the shopping venues scale. Subsequent analyses use the shortened versions of these scales. The reliabilities of the scales in their final form are presented in Table 2.

The self-attributed need for uniqueness and consumer dispositions. Hypotheses 1 through 5 were tested by correlating the study-specific measure of SANU with the measures of desire for scarce products, consumer innovativeness, consumer susceptibility to normative influence, preference for unique shopping venues, and desire for customized products (Table 3). SANU was positively and significantly correlated with all of the consumer dispositions except susceptibility to normative influence. Thus, Hypotheses 1, 2, 4, and 5 were supported, but Hypothesis 3 was not. The failure to support Hypothesis 3 suggests that the desire for unique products and the desire for commonly owned products are not opposite ends of a continuum. People own many products at the same time, and 
consumers who desire distinctive products may simultaneously desire other products that are more common.

The tendency to pursue uniqueness through consumption. We hypothesized that there were individual differences in the tendency to seek uniqueness through consumer products and that this desire to be a unique consumer mediates the relationship between the need for uniqueness and various consumer dispositions (Hypothesis 6). This hypothesis was tested in two path analyses using LISREL (Joreskog \& Sörbom, 1993).

Table 3

Correlations Between the Need for Uniqueness and Various Consumer Dispositions

\begin{tabular}{lcc}
\hline & \multicolumn{2}{c}{ Correlation with } \\
\cline { 2 - 3 } \multicolumn{1}{c}{ Consumer disposition } & $\begin{array}{c}\text { Authors' } \\
\text { SANU scale }\end{array}$ & $\begin{array}{c}\text { Snyder \& } \\
\text { Fromkin's scale }\end{array}$ \\
\hline $\begin{array}{l}\text { Desire for scarce products } \\
\text { Consumer innovativeness }\end{array}$ & $.34^{*}$ & .06 \\
$\begin{array}{l}\text { Consumer susceptibility to normative } \\
\text { influence }\end{array}$ & $.31^{*}$ & $.28^{*}$ \\
Preference for unique shopping venues & .07 & $-.42^{*}$ \\
Desire for customized products & $.30^{*}$ & $.26^{*}$ \\
\hline$* p<.01$. & $.32^{*}$ & .02 \\
\hline
\end{tabular}

First, a model in which NU acts as a direct cause of various consumer dispositions was estimated using this study's measures of: (a) SANU, (b) desire for scarce products, (c) consumer innovativeness, (d) consumer susceptibility to normative influence, (e) preference for unique shopping venues, and (f) desire for customized products. Figure 1 depicts the hypothesized model and shows the standardized LISREL path estimates. All of the path coefficients except the one to consumer susceptibility to normative influence were significant, reflecting the correlations reported above. However, the covariance structure implied by this model did not fit the data very well, $x 2(10)=91.54, p<, 001, A G F I=.57$. 


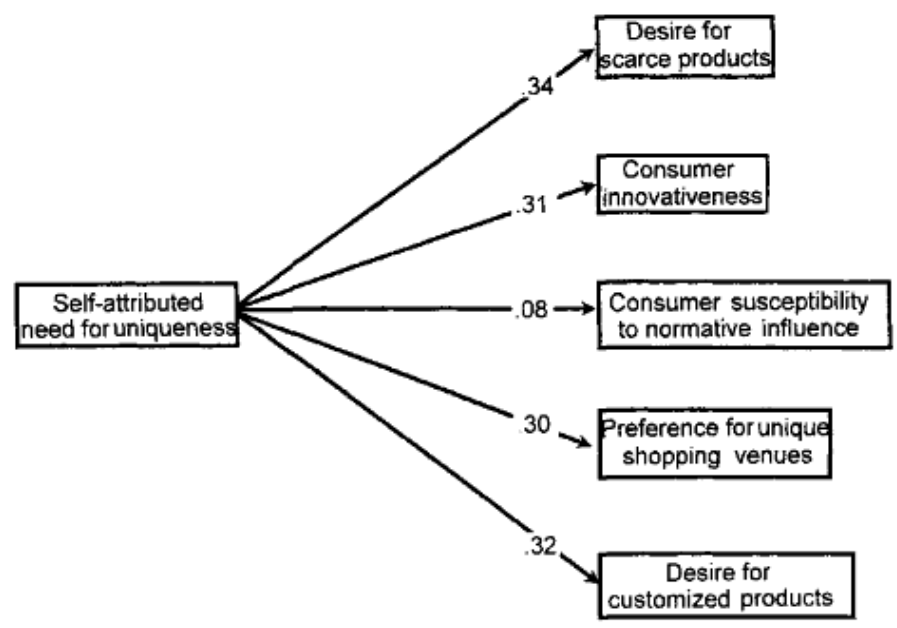

Figure 1. LISREL estimates for a model depicting need for uniqueness effects on various consumer dispositions.

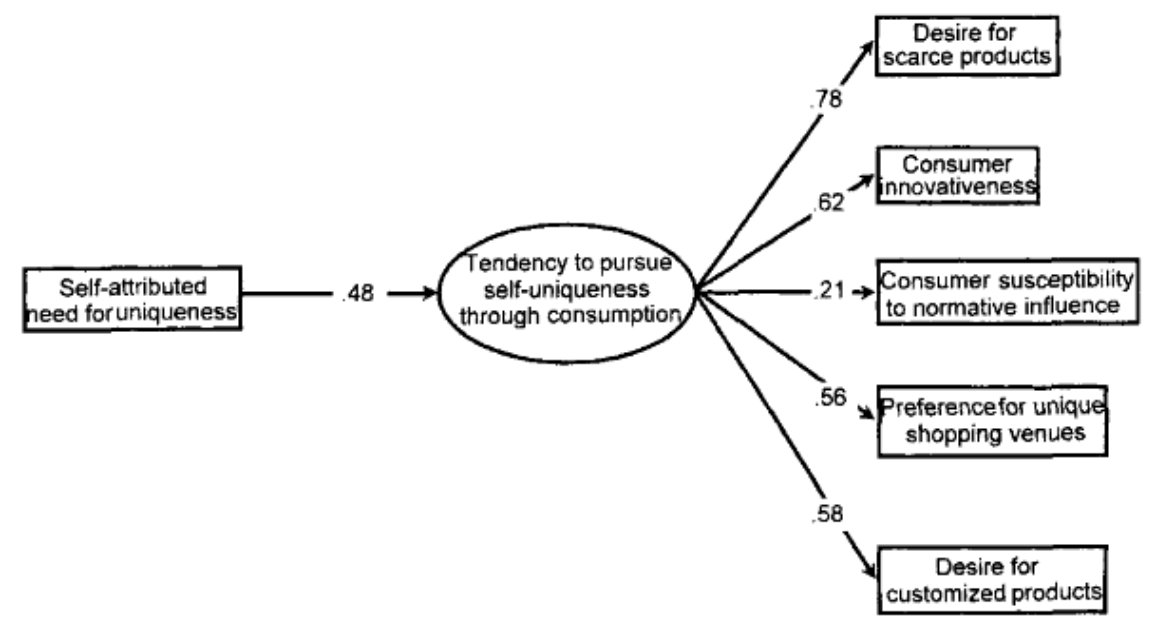

Figure 2. Standardized LISREL estimates for a model depicting a latent variable mediator of need for uniqueness effects on various consumer dispositions.

Second, a model in which a latent variable mediates the causal effects of NU on the measured consumer dispositions was estimated. Figure 2 depicts this model and shows the standardized LISREL path estimates. Again, all but one of the path coefficients were significant. The measures of the desire for scarce products, consumer innovativeness, preference for unique shopping venues, and the desire for customized products all loaded highly $(.56<$ rs 5.78) on a latent variable that was more highly correlated $(r=.48)$ with SANU than were the individual measures. Consumer susceptibility to normative influence did not load significantly on the latent variable, providing further evidence that consumer conformity is independent of uniqueness motivations. The overall fit between the covariance structure 
implied by the model and that actually observed was very good, $x 2(9)=9.33, \mathrm{~ns}, \mathrm{AGFI}=.95$. Moreover, a significance test comparing the goodness of fit of this model with the one omitting the latent variable indicated that adding the latent variable significantly improved the model's goodness of fit, $x 2(1)=82.2$ $1, p<.001$. Thus, Hypothesis 6 was supported. A tendency to pursue uniqueness through consumer products does appear to mediate the relationship between NU and specific consumer dispositions.

Snyder and Fromkin's scale. We also assessed the relationships between Snyder and Fromkin's (1977) measure of the NU and each of the consumer dispositions in this study. In contrast to the previous results, Snyder and Fromkin's scale was significantly correlated with consumer susceptibility to normative influence (negatively), as well as with consumer innovativeness and preference for unique shopping venues (positively), but was not correlated with the desire for either scarce or customized products (Table 3). Moreover, Snyder and Fromkin's scale was unrelated ( $r=$ $.18, n s)$ to the latent variable underlying these consumer dispositions when a LISREL analysis of a model similar to that in Figure 2 was performed. This pattern of results suggests that the three significant relationships involving Snyder and Fromkin's scale reflect something other than the pursuit of uniqueness through consumption. We believe that they reflect a lack of concern for the reactions of others. It is understandable that people who are unconcerned about the reactions of others would score high on Snyder and Fromkin's scale and would be relatively less susceptible to normative influence, more inclined to adopt products before they become popular, and more inclined to shop at unpopular stores. In summary, our data are consistent with our earlier observation that Snyder and Fromkin's (1 977) scale does not measure the NU so much as the willingness to be publicly nonconforming.

Discussion

Theoretical implications. The results of this study provide evidence that individual differences in uniqueness motivation underlie several consumer dispositions. Consistent with our hypotheses, consumers' preferences among shopping venues and consumers' desires for scarce, innovative, and customized products were related to consumers' dispositional NU. This study is not the first to examine these relationships, but most of the previous studies have produced weak and inconsistent results and have remained unpublished. The relatively strong results observed in this study may be attributable to our use of consumer dispositions rather than single behaviors and to our use of a different measure of the NU. 
Second, the results of this study provide evidence for the existence of a dispositional tendency to pursue uniqueness through consumption. Measures of the desire for scarce products, the desire for customized products, the preference for unique shopping venues, and the willingness to adopt innovative new products all loaded on a common latent variable. Moreover, this latent variable mediated the relationships between the measured consumer dispositions and the SANU. These results suggest that uniqueness striving is domain specific and that some people pursue uniqueness through consumption more than do others. Thus, this study identifies a new personality construct that is more directly and more strongly related to consumers' attitudes and behaviors than is the general NU.

Finally, the results of this study provide evidence that the NU is independent of consumer susceptibility to normative influence. Consumers' scores on Bearden et al.'s Susceptibility to Normative Influence subscale were unrelated to both the SANU and the latent variable reflecting the tendency to pursue uniqueness through consumption. These findings are contrary to the results of previous studies (Schroeder, 1990; Tepper, 1994) and to Hypothesis 3. However, the previous studies used Snyder and Fromkin's (1977) scale, which appears to measure the tendency to be publicly nonconforming rather than the need for uniqueness. When it is the need for uniqueness that is measured, Hypothesis 3 does not appear to be supported. In retrospect, the failure to support this hypothesis should not be surprising. People need to fit in and belong as well as to be distinctive and unique (Brewer, 199 1). It seems reasonable that these needs function independently and that people use some products to foster uniqueness while also using other products to foster belonging and conformity.

Marketing implications. In addition to furnishing insight into the consumer psyche, the findings of this study also provide several implications for marketing practitioners:

Our finding that the need for uniqueness is related to consumer innovativeness suggests that uniqueness appeals may be particularly effective in the promotion of new products.

- Our finding that the need for uniqueness and the susceptibility to conformity pressures function independently implies that marketers can use uniqueness appeals without fear of alienating consumers who are highly susceptible to normative influence.

- Our finding that uniqueness-seeking consumers tend to prefer smaller and less popular retail outlets implies that the managers of such outlets should stock and 
promote unique merchandise in order to capitalize on their customers' tastes.

- Our finding that some people seem to have a propensity to seek uniqueness through consumption provides a potential basis for psychographic segmentation. If these consumers could be identified and targeted, it is likely that they would prove to be a willing market for a variety of products and services possessing unique attributes.

Future directions for research. We foresee several directions that future research could possibly take. First, the manifestations of uniqueness seeking in consumer behavior could be further explored. As we noted previously, research in this area is surprisingly scant. Although the topic of preference for scarce and innovative products has received some attention, other areas remain practically unexplored. Among the unexamined aspects of consumer behavior potentially related to uniqueness motivations are consumers' preferences for lone versus group consumption experiences (e.g., a group vacation), consumers' participation in physically risky activities (e.g., skydiving) in which few others are willing to engage, and consumers' possession and use of old, outmoded products that others have abandoned. Future research could examine these and other potential manifestations of the pursuit of self- uniqueness through consumption.

A second potential avenue for future research is the development of a new measure of the NU. As discussed earlier, Snyder and Fromkin's (1977) scale seems to place undue emphasis on socially risky behaviors, and therefore might better be described as a measure of public nonconformity than of uniqueness. Certainly, the SANU measure used in this study is a promising alternative. We have demonstrated here that this measure is internally consistent and statistically related to several theoretically relevant consumer dispositions. However, additional research demonstrating the validity of the scale would be desirable.

Third, an individual differences measure of the tendency to pursue uniqueness in the consumer domain could be developed, validated, and used. The findings of our study indicate the existence of this domain-specific manifestation of uniqueness motives, and provide empirical support for Snyder's (1992) and Sirgy's (1993) argument that a consumer-specific uniqueness measure would be more successful than Snyder and Fromkin's (1 977) scale at predicting consumer behaviors. We have already developed one measure of this dispositional desire for unique consumer products (Lynn \& Harris, 1997). In addition to providing a more powerful predictor of consumer behavior, this measure could be used as a dependent variable in studies of the factors contributing to the development of individual differences in the tendency to pursue uniqueness through consumption. 


\section{References}

Atlas, M. S., \& Snyder, C. R. (1978). The effects of need for uniqueness upon valuation of scarce and nonscarce objects. Unpublished honors thesis, Psychology department, University of Kansas, Lawrence, KS.

Bearden, W. O., Netemeyer, R. G., \& Teel, J. E. (1989). Measurement of consumer susceptibility to interpersonal influence. Journal of Consumer Research, 15, 473-48 1.

Belk, R. W. (1989). Possessions and the extended self. Journal of Consumer Research, 15, 139-168.

Belk, R. W., Sherry, J. F., \& Wallendorf, M. (1988). A naturalistic inquiry into buyer and seller behavior at a swap meet. Journal of Consumer Research, 15, 139-168.

Brehm, J. W., Stires, L. K., Sensenig, J., \& Shaban, J. (1966). The attractiveness of an eliminated choice alternative. Journal of Experimental Social Psychology, 2, 30 1-3 13.

Brewer, M. B. (199 1). The social self: On being the same and different at the same time. Personality and Social Psychology Bulletin, 17,475-482.

Brock, T. C. (1968). Implications of commodity theory for value change. In A. Greenwald, T. C. Brock, \& T. M. Ostrom (Eds.), Psychological foundations of attitudes (pp. 243-275). New York, NY: Academic.

Burns, D. J. (1987). The effects of uniqueness seeking and sensation seeking upon innovative behavior and the adoption process. Unpublished doctoral dissertation, Department of Marketing, Kent State University, Kent, $\mathrm{OH}$.

Burns, D.J. (1989). The need for uniqueness and the adoption process. Journal of Midwest Marketing, 4, 28-37.

Burns, D.J. (1 990). Need for uniqueness and the adoption process: What about male consumers. In M-t. Lee (Ed.), Proceedings (pp. 22-24). Minneapolis, MN: Decision Sciences Institute.

Burns, D.J. (1994). The need for uniqueness and regional shopping malls: An exploration into the meanings of mall choice. Unpublished manuscript, Youngstown State University, Youngstown, $\mathrm{OH}$.

Burns, D. J., \& Krampf, R.F. (1992). Explaining innovative behavior: Uniqueness-seeking and sensationseeking. International Journal of Advertising, 11, 227-237.

Burns, D. J., \& Rayman, D. M. (1991). Need for uniqueness and the adoption process. In E.A. Tune \& J.N.D. Gupta (Eds.), Proceedings (pp. 182-184). Indianapolis, IN: Decision Sciences Institute.

Codol, J. P. (1984). Social differentiation and nondifferentiation. In H. Tajfel (Ed.), The social dimension (pp. 3 14-337). Cambridge, England: Cambridge University Press. 
Darley, W. K., \& Lim, J. (1993). Store-choice behavior for pre-owned merchandise. Journal of Business Research, 27, 17-3 1.

Dutcher, L. W. (1975). Scarcity and erotica: An examination of commodity theory dynamics. Unpublished doctoral dissertation, Psychology Department, Southern Illinois University, Carbondale, IL.

Duval, S. (1972). Conformity on a visual task as a function of personal novelty on attitudinal dimensions and being reminded of the object status of the self: Unpublished doctoral dissertation, Psychology Department, University of Texas, Austin, TX.

Epstein, S. (1979). The stability of behavior: I. On predicting most of the people much of the time. Journal of Personality and Social Psychology, 37, 1097-1 126.

Fromkin, H. L. (1968). Affective and valuational consequences of self-perceived uniqueness deprivation. Unpublished doctoral dissertation, Department of Psychology, Ohio State University, Columbus, $\mathrm{OH}$.

Fromkin, H. L. (1970). Effects of experimentally aroused feelings of undistinctiveness upon valuation of scarce and novel experiences. Journal of Personality and Social Psychology, 16, 521-529.

Fromkin, H. L. (1971). A social psychological analysis of the adoption and diffusion of new products and practices from a uniqueness motivation perspective. In D. M. Gardner (Ed.), Proceedings of the 2nd annual Conference of the Association for Consumer Research (pp. 464-469). College Park, MD: Association for Consumer Research.

Fromkin, H. L. (1972). Feelings of interpersonal undistinctiveness: An unpleasant affective state. Journal of Experimental Research in Personality, 6, 178-182.

Fromkin, H. L., Williams, J. J., \& Dipboye, R. L. (1973). Birth-order, responses to need-for-uniqueness scale items and valuation of scarce commodities. Cited in H. L. Fromkin, The psychology of uniqueness: avoidance of similarity and seeking of differences (Working Paper No. 438). West Lafayette, IN: Krannert Graduate School of Industrial Administration, Purdue University.

Goldsmith, R. E., \& Hofacker, C. F. (1991). Measuring consumer innovativeness. Journal of Marketing Science, 19,209-22 1.

Gutman, J., \& Mills, M. K. (1982). Fashion life style, self-concept, shopping orientation, and store patronage: An integrative analysis. Journal of Retailing, 58, 64-86.

Hudson, D. D. (1979). The effects of censorship and need for uniqueness on the valuation of messages. Unpublished doctoral dissertation, Speech Communication department, University of Denver, Denver, $\mathrm{CO}$.

James, W. (1890). The principles of psychology (Vol. 1). New York, NY: Henry Holt. 
Joreskog, K., \& Sörbom, D. (1993). LISREL 8: Structural equation modeling with the SIMPLIS command language. Hillsdale, NJ: Lawrence Erlbaum.

Lemaine, G. (1974). Social differentiation and social originality. European Journal of Social Psychology, 4, $17-52$.

Lynn, M. (1 987). The effects of scarcity on perceived value: Investigations of commodity theory. Unpublished doctoral dissertation, Psychology Department, Ohio State University, Columbus, $\mathrm{OH}$.

Lynn, M. (1989). Scarcity effects on value: Mediated by assumed expensiveness? Journal of Economic Psychology, 10,257-274.

Lynn, M. (1991). Scarcity effects on value: A quantitative review of the commodity theory literature. Psychology and Marketing, 8, 43-57.

Lynn, M. (1992). The psychology of unavailability: Explaining scarcity and cost effects on value. Basic and Applied Social Psychology, 13, 3-8.

Lynn, M., \& Harris, J. (1997). The desire for unique consumer products: A new individual differences scale. Psychology and Marketing, 14, 601 - 616.

Maslach, C., Stapp, J., \& Santee, R. T. (1985). Individuation: Conceptual analysis and assessment. Journal of Personality and Social Psychology, 49, 729-738.

Myers, J. H., \& Robertson, T. S. (1972). Dimensions of opinion leadership. Journal of Marketing Research, 9, 41-46.

Okamoto, K. (1983). Effects of excessive similarity feedback on subsequent mood, pursuit of difference, and preference for novelty on scarcity. Japanese Psychological Research, 25, 69-77.

Pollay, R. W. (1984). The identification and distribution of values manifest in print advertising 19001980. In R. E. Pitts, Jr. \& A. G. Woodside (Eds.), Personal values and consumer psychology (pp. 11 1-135). Toronto, Canada: Lexington.

Powell, F. A. (1974). The perception of self-uniqueness as a determinant of message choice and valuation. Speech Monographs, 41, 163-1 68.

Reingen, P. H., Foster, B. L., Brown, J. J., \& Seidman, S. B. (1984). Brand congruence in interpersonal relations: A social network analysis. Journal of Consumer Research, 11, 771-783.

Ringold, D. J. (1988). Consumer response to product withdrawal: The reformulation of Coca-Cola. Psychology and Marketing, 5, 189-210.

Robertson, T. S. (1971). Innovative behavior and communication. New York, NY: Holt, Rinehart, and Winston. 
Rogers, E. M. (1 983). Diffusion of innovations (3rd ed.). New York, NY: Free Press.

Schroeder, J. E. ( 1990). Psychological foundations of consumer preferences: The role of affiliation, conformity, individuation and uniqueness. Unpublished doctoral dissertation, Psychology Department, University of California at Berkeley, Berkeley, CA.

Sherry, J. F., Jr. (1990). A sociocultural analysis of a midwestern American flea market. Journal of Consumer Research, 17, 13-30.

Sirgy, M. J. (1993). Review of the psychology of unavailability: Explaining scarcity and cost effects on value. Journal of Marketing Research, 30,395-399.

Smith, A. (1937). The wealth of nations. New York, NY: Random House. (Original work published 1776)

Snyder, C. R. (1992). Product scarcity by need for uniqueness interaction: A consumer Catch-22 carousel? Basic and Applied Social Psychology, 13,

Snyder, C. R., \& Fromkin, H. L. (1977). Abnormality as a positive characteristic: The development and validation of a scale measuring need for uniqueness. Journal ofAbnorma1 Psychology, 86, 5 18527.

Snyder, C. R., \& Fromkin, H. L. (1980). Uniqueness: The human pursuit of difference. New York, NY: Plenum.

Szybillo, G. J. (1973). The effects of price and scarcity on the valuation of fashion opinion leaders and nonopinion leaders. Unpublished doctoral dissertation, Department of Psychology, Purdue University, West Lafayette, IN.

Szybillo, G. J. (1975). A situational influence on the relationship of a consumer attribute to new-product attractiveness. Journal of Applied Psychology, 60, 652-655.

Tepper, K. (1994). Need for uniqueness: An individual difference factor affecting nonconformity in consumer responses. In C. W. Park \& D. C. Smith (Eds.), Marketing theory and applications: Proceedings of the 1994 AMA Winter Educators' Conference. Chicago, IL: American Marketing Association.

Venkatesan, M. (1966). Experimental study of consumer behavior conformity and independence. Journal of Marketing Research, 3, 384-387.

West, S. G. (1975). Increasing the attractiveness of college cafeteria food: A reactance theory perspective. Journal of Applied Psychology, 60,656-658.

Witt, R. E., \& Bruce, G. D. (1972). Group influence and brand choice congruence. Journal of Marketing Research, 9,440-443. 
Worchel, S., Lee, J., \& Adewole, A. (1975). Effects of supply and demand on ratings of object value. Journal of Personality and Social Psychology, 32, 906-914.

Ziller, R. C. (1964). Individuation and socialization. Human Relations, 17, 34 1-360.

Appendix

Self-Attributed Need for Uniqueness Scale

1. I prefer being ___ different from other people.

(a) no, (b) slightly, (c) moderately, (d) very, (e) extremely

2. Being distinctive is important to me.

(a) not at all, (b) slightly, (c) moderately, (d) very, (e) extremely

3. I___ intentionally do things to make myself different from those around me.

(a) never, (b) seldom, (c) sometimes, (d) often, (e) always

4. I have a need for uniqueness.

(a) weak, (b) slight, (c) moderate, (d) strong, (e) very strong

Desire for Scarce Products Scale

1. I am very attracted to rare objects.

2. I am more likely to buy a product if it is scarce.

3. I prefer rare products over more common ones.

4. I enjoy having products that are in limited supply.

5. I find limited editions of products especially desirable.

6. When I learn that a product is scarce, I want it more.

7. I enjoy possessing rare objects.

Desire for Customized Products Scale

1. I rarely pass up the opportunity to order custom features on the products I buy.

2. I often put patches and/or stickers on my possessions to make them reflect who I am.

3. I have always wanted a pen and pencil set with my name engraved on them.

4. I feel no need to personalize the products I buy. (reversed for scoring)

5. The idea of having my initials monogrammed on some of my clothes appeals to me.

6. I would prefer to have things custom made than to have them ready made. 
Preference for Unique Shopping Venues Scale

1. I would rather shop at a store that few others go to than shop at a store that everyone goes to.

2. I tend to shop at small unusual stores.

3. I prefer small specialty shops to large department stores.

4. I shop at antique shops, flea markets and/or thrift shops.

5. I would rather buy something from a catalogue than go to a mall to buy it.

6. When shopping, I tend to avoid malls.

7. I prefer little-known stores to well-known stores.

Note. For the Self-Attributed Need for Uniqueness Scale, subjects responded with the number of the word that best completed the statement. For all other scales, subjects chose the number from a fivepoint scale labeled strongest disagreement to strongest agreement that best reflected their level of agreement with each statement. See previously published sources for Snyder and Fromkin's (1977) Need for Uniqueness Scale, Bearden, Netemeyer, and Teel's (1 989) Susceptibility to Normative Influence Scale, and Goldsmith and Hofacker's (1 99 1) Product-Specific Innovativeness Scale. 